University for Business and Technology in Kosovo

UBT Knowledge Center

UBT International Conference

2016 UBT International Conference

Oct 28th, 9:00 AM - Oct 30th, 5:00 PM

\title{
The Design of an Extradosed Bridge
}

Drilon Rraci

University of Maribor, rracidrilon@gmail.com

Milan Kuhta

University of Maribor, miso.kuhta@um.si

Follow this and additional works at: https://knowledgecenter.ubt-uni.net/conference

Part of the Engineering Commons

\section{Recommended Citation}

Rraci, Drilon and Kuhta, Milan, "The Design of an Extradosed Bridge" (2016). UBT International

Conference. 9.

https://knowledgecenter.ubt-uni.net/conference/2016/all-events/9

This Event is brought to you for free and open access by the Publication and Journals at UBT Knowledge Center. It has been accepted for inclusion in UBT International Conference by an authorized administrator of UBT Knowledge Center. For more information, please contact knowledge.center@ubt-uni.net. 
The Design of an Extradosed Bridge

\title{
The Design of an Extradosed Bridge
}

\author{
Drilon Rraci ${ }^{1}$, Milan Kuhta ${ }^{2}$ \\ ${ }^{1,2}$ University of Maribor, Faculty of Civil Engineering,Traffic Engineering and \\ Architecture, Smetanova ulica 17, 2000 Maribor, Slovenia \\ rracidrilon@gmail.com ${ }^{1}$, miso.kuhta@um.si ${ }^{2}$
}

\begin{abstract}
Bridges are attractive structures consisting of great interest in both aspects: professional and the general public one. At the end of 19. and start of 20. century, one of the most relevant contributions to bridges engineering has been the introduction of prestressed technique, aiming to be a great solution to the need of controlling stress on elements in bridges. The purpose of this paper is to discuss and analyze the design model and structural behavior of an Extradosed bridge. The strategies and factors that must be considered in the design of an Extradosed bridge are included in this paper. The structural behavior, materials utilization and structural analysis were performed in accordance with the SOFiSTiK package.
\end{abstract}

Keywords: extradosed bridge, prestressing, design, SOFiSTiK

\section{Introduction}

The First Extradosed Bridge in Slovenia designed by Ponting Consulting Engineers Ltd [1], in 2005, has been considered as a main reference in this paper. This bridge, named "Puch Bridge" after the famous Slovenian inventor, was opened to traffic in May 2007. A scholar project design example based on "Puch Bridge" is discussed and analyzed in this paper [7].

\subsection{Brief history of Extradosed Bridges}

The first application of extradosed prestressing was Mathivat's proposal for the Arrêt-Darré viaduct with precast box girder sections (Mathivat 1987), developed in 1982-1983 [2]. In 1988 Jacques Mathivat proposed the concept of extradosed cables that are external prestressed tendons allocated in the deck's outer and upper side, which are diverted by low size masts [5]. Six years later the first prestressed extradosed bridge was built in Japan: Odawara Blueway Bridge [6]. Afterwards, it was found that the design of the extradosed bridge significantly saves $30 \%$ of the material, in comparison to conventional free cantilever constructed as a girder segment bridge. The idea of Mathivat was to substitute the internal tendons in the top flange of a box girder for external cables above the running surface, deviated over the piers by stub columns and anchored inside the box girder, which he called 'extradosed cables' [2]. Extradosed bridges are transitional between girders and cable-stayed bridges. Most such bridges are erected in balanced cantilever, and may be cast-in-situ or precast segmental. Virlogeux explains (1999) that the concept was partially motivated by a 'distortion of code 
Book of Proceedings

International Conference on Civil Engineering, Infrastructure and Environment

specifications' to use stay cables more efficiently, since an allowable stress of $0.65 \mathrm{f}_{\text {pu }}$ could be used for design of the cables instead of the value of $0.45 \mathrm{f}_{\text {pu }}$ typically adopted for cable-stayed bridges [2].

\section{Design Concept}

\subsection{Environmental Conditions and Other Restrictions}

In the event of designing a structure such as Extradosed Bridge, it is necessary to take environmental conditions into account in case of protecting the reinforcement and prestressing cables against corrosion. The thickness of the concrete covers of the individual elements shall be calculated on the basis of their exposure class. In this case the following conditions according to European Standard Eurocode 2 have been considered:

- Exposure class XD3;

- Design working life of 100 years;

- Normal supervision during its implementation;

- Normal inspections and maintenance during its construction and utilize phase;

- The basic structural class of the structure S5.

Furthermore, other significant restrictions and conditions such as road geometry, foundation conditions and surrounding terrain, that affects the technical design of the relevant bridge, must be taken into consideration.

\subsection{Structure description}

The road bridge is thought to be built over the existing road and watercourse in the vicinity of the city of Maribor. The conceptual geometry of the bridge is set out in accordance with its level course of the road and its characteristic profile. Its level represents the surface of the bridge elements aligned with the altitude of the carriageway. The width of the bridge is set out as result of its characteristic profile. Longitudinal profile of the carriageway consists of very small inclination, therefore it has been ignored in the overall structural analysis. Due to very difficult conditions of the valley, the design of an extradosed bridge, consists of longitudinal disposition with the spans of 56,0 + $(2 \times 97,0)+56,0=$ $306,0 \mathrm{~m}$ has been proved as the most suitable solution for bridging the obstacles.

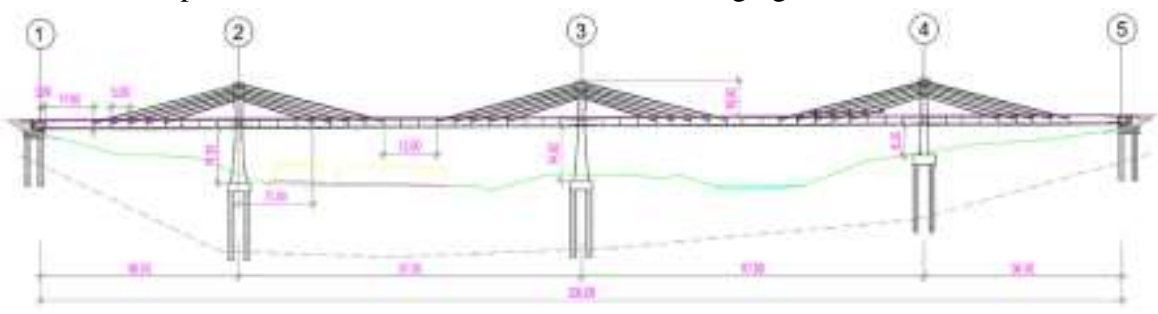

Fig. 1. Longitudinal disposition of the structure. 
A box girder has been chosen to provide the most efficient section for casting, with the overall width of $13,63+0,99=14,62 \mathrm{~m}$, and a constant height of 2,50 m. Box girder is at the supports of the deck rigidly embedded in the tower, as it is shown in Fig. 2.

As the structure represents a newer technology in bridge building, it shall be noticed that the extradosed bridge girder could be more slender than a normal continuous girder, and the pylon could be lower than the pylon for cable-stayed systems.
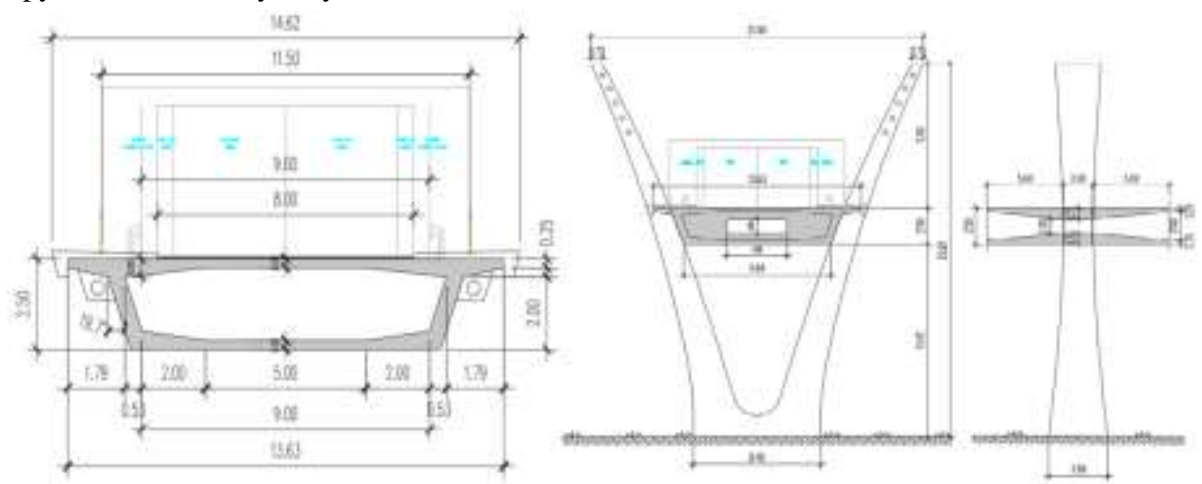

Fig. 2. Typical cross-section of extradosed part of the bridge. A typical box girder through the spans (left), and the supports (right) of the structure.

The bridge consists of an overall length of $306,0 \mathrm{~m}$ with two abutments and three intermediate piers. The total width of the bridge is $14,62 \mathrm{~m}$. The superstructure consists of three main elements:

- box girder roadway structure;

- low pylons;

- inclined cables.

The roadway structure consists of a trapezoidal prestressed RC box of structural height 2,50 m (Fig. 2). The web thickness is $0,50 \mathrm{~m}$, while the upper slab is $13,63 \mathrm{~m}$ wide and the bottom slab $10,00 \mathrm{~m}$. The slab thickness varies from 0,25 to $0,50 \mathrm{~m}$. The cantilever is $1,25 \mathrm{~m}$ long, at the fixing point 0,50 $m$ thick and rebar reinforced. The box girder is made of concrete of compressive strength C35/45.

The structure consists of bonded tendons (negative and positive) in the girder, vertical prestressing bars in pylons, and prestressed by extra reinforced cable-stayed (extrados cables) mounted at intermediate pylons. The cables consist of nominal diameter 0,62 " and the section $150 \mathrm{~mm}^{2}$, with a very low relaxation $\left(<2.50 \%\right.$ at the stress $0,7 \mathrm{f}_{\mathrm{pu}}$ in the $1000 \mathrm{~h}$ test $)$, and of quality $\mathrm{f}_{\mathrm{py}} / \mathrm{f}_{\mathrm{pu}}=1600 / 1860 \mathrm{~N} / \mathrm{mm}^{2}$ selected as $15 \times 0,62$ " with a nominal stressing force of $3038 \mathrm{kN}$ (about. $0,70 \mathrm{f}_{\mathrm{pu}}$ ) in case of free length 
Book of Proceedings

International Conference on Civil Engineering, Infrastructure and Environment

in the upper part of the girder, and $22 \times 0,62$ " with a nominal stressing force of $4572 \mathrm{kN}$ (about. 0,70 $\mathrm{f}_{\mathrm{pu}}$ ) for positive tendons in the bottom part of the girder.

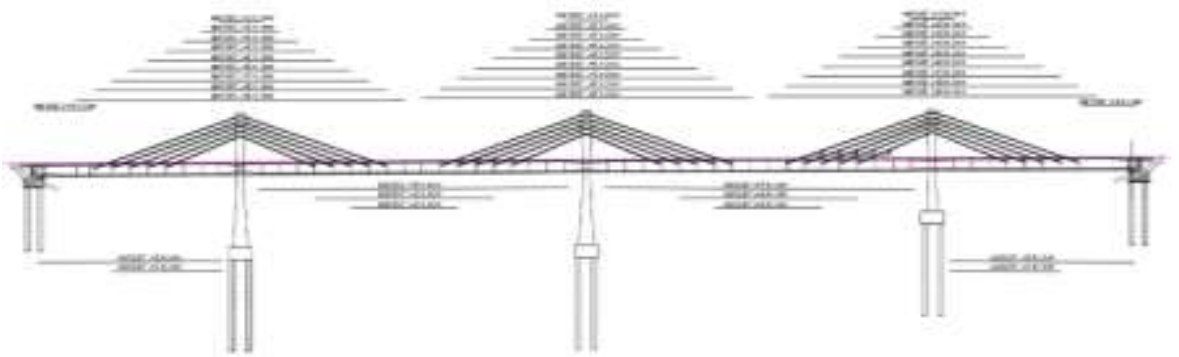

Fig. 3. Scheme of prestressing cables.

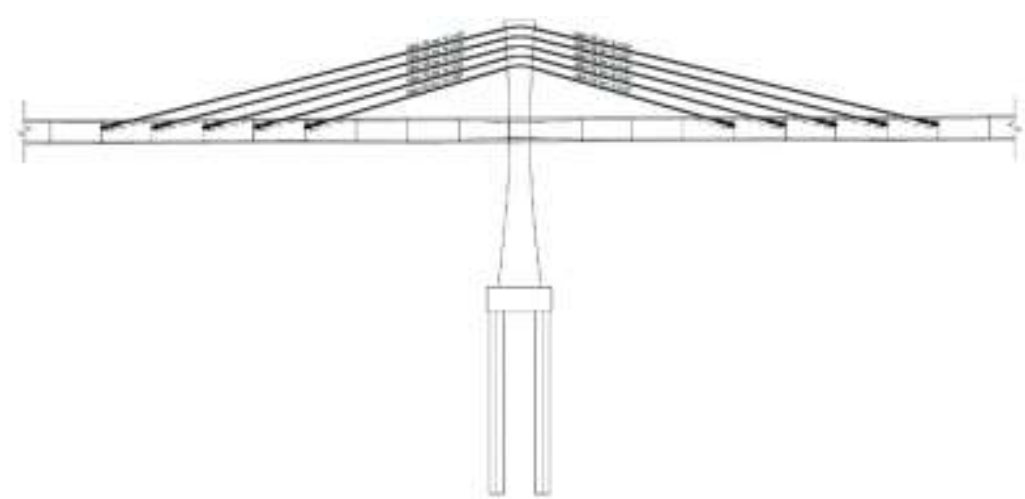

Fig. 4. Scheme of cable-stayed anchored to concrete webs.

The structure in its design aspect as a mixed load bearing system represents the interface between the conventional deck with rigid - bearing lintel and cables inside its cross-section and suspension bridges, which are the main load-bearing elements of the backstay.

The girder structure shall be constructed in accordance with the progressive technology-the balanced cantilever method. In this principle, movable scaffolding with segment length of $5 \mathrm{~m}$ shall be used for erection [1].

At the foundation area, the soil mechanics data as well as the execution feasibility, structure maintenance and the hydraulic consequences are taken into account. For the simplicity reasons we took the same characteristics of the soil for the whole structure into account. In the structural analysis the following values of soil reaction module $c_{v}$ has been considered

-Clay to a depth of $20,00 \mathrm{~m}: c_{v}=25000 \mathrm{kN} / \mathrm{m} 3$;

-Soil type at the supporting base to a depth of 20, $00 \mathrm{~m}: c_{v}=150000-200000 \mathrm{kN} / \mathrm{m} 3$. 


\section{Computation Model}

The design of the structure was performed in accordance with the software package SOFiSTiK. Basically the longitudinal analysis of the structure, described in the sections above, is the primary task of this paper. Thus, the deck structure, its pylons and pilots are modeled as »BEAM« elements, while Cable-stayed has been modeled as »CABLE« elements.

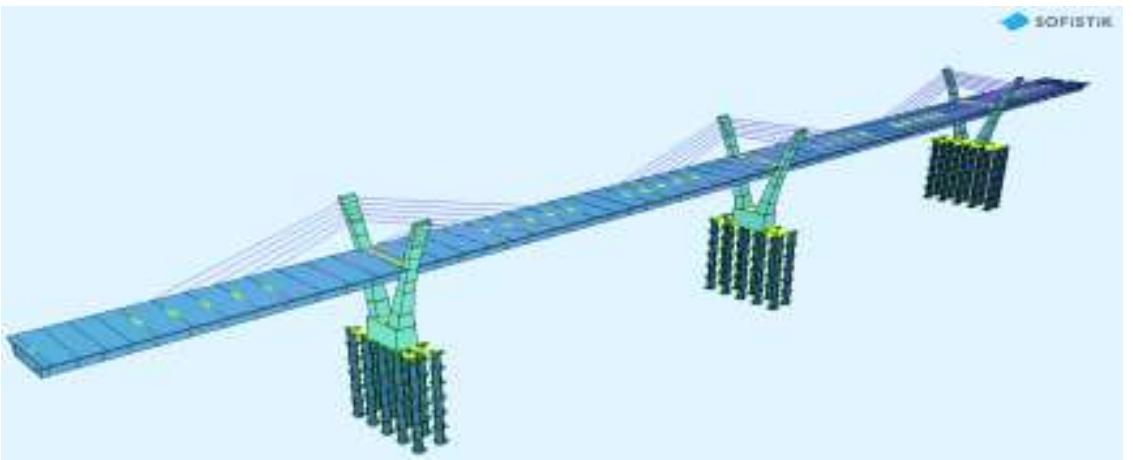

Fig. 5. Computation model of the structure set out in accordance with the software package SOFiSTiK.

The ground type in which the piles were modeled, as elastic foundation using linearly elastic springs, also known as Winkler model [3], the flexibility of foundation was chosen basically in the appropriate way to the characteristics of the soil. Nominal values of material and geometric parameters of each element of the structure and the relevant static properties, are estimated by the designers and set out in accordance with the software package SOFiSTiK. The bridge deck is modelled based on the balanced cantilever method with the help of inclined extrados cables. In this case, the "extrados cables" shall be assembled near the bridge and then mounted as a whole through saddles in the pylon to anchorages.

The pylons consist of a rectangular cross-section of about 1,50/2,00 m, while the strength of concrete in this case is partially used as C45/55 and partially as C60/75. Geometric parameters of the pylon are generally detailed in Fig. 2. All the supports are designed on deep foundation with piles of diameter $\Phi 150 \mathrm{~cm}$. Foundation on ten piles of diameter $\Phi 150 \mathrm{~cm}$ is used in the event of designing the piers of the structure.

Load cases of the whole structure are manually analyzed and set out in accordance with the relevant European Standard Eurocodes. Each relevant verification at Ultimate limit state and Serviceability limit state is set out in accordance with the software package, while in the same time their useful limitations are checked in accordance with the Eurocode 2. 
Book of Proceedings

International Conference on Civil Engineering, Infrastructure and Environment

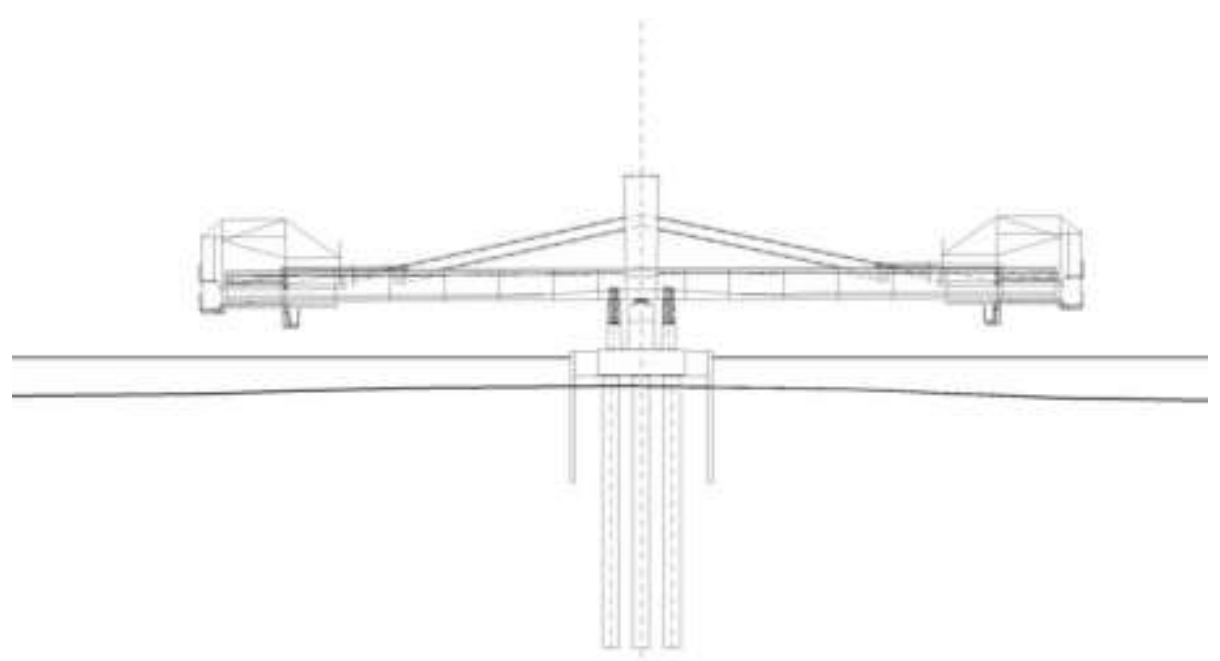

Fig. 6. The balanced cantilever construction with the help of "extrados cables" [1].

Furthermore, based on this designing procedure the structural analysis of the construction stages of the structure has been set out with the help of SOFiSTiK software package. As an example of construction stage analysis, envelope of bending moments of the construction stages is shown in Fig. 7.

Fig. 7. The envelope of bending moments of the construction stages of the structure.

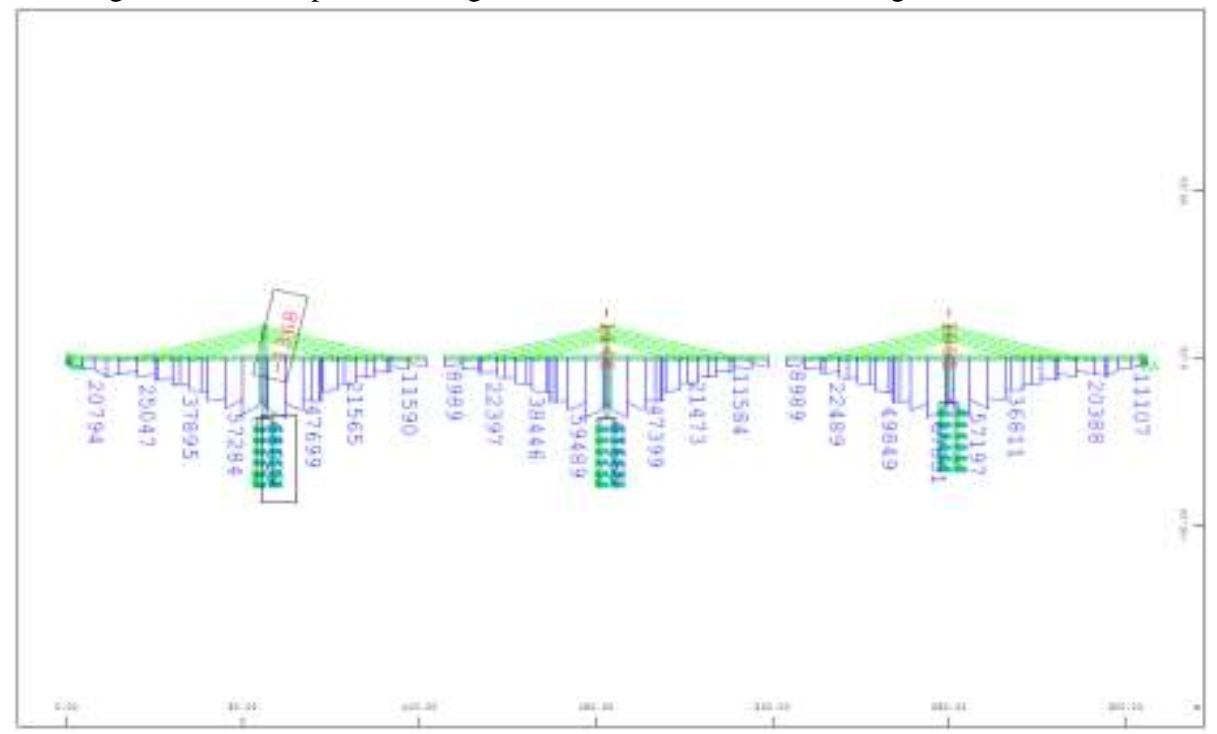


The Design of an Extradosed Bridge

\section{Conclusion}

In the event of analyzing the structure as it has been described and discussed in this paper, the main domain has been on a longitudinal analysis of the structure as a general process. During the process of determining the comprehensive analysis of the structure, it was necessary to create a separation of spatial structural system into several in-plane sub-models [4], regardless to carry out the relevant analysis of the deck structure in its transverse direction. Therefore, a FEM model consisting of several planar finite elements has been modelled and set out in this case. Based on the results obtained from this task, it can be verified that, the live load causes only a small amount of stress variation in the cables placed in the structure, basically represents an essential difference between "extradosed" and "cablestayed" bridges.

\section{References}

1. Viktor Markelj, Structural Eng., Manager, PONTING d.o.o. Maribor: The First Extradosed Bridge in Slovenia. Vol. 20. No. 4. Structural Engineering International, Nov. 4. 2010

2. Konstantinos Kris Mermigas: Behaviour and Design of Extradosed Bridges. MSc Thesis. University of Toronto. Toronto (2008)

3. Sharabony Adhikary: Modelling of Soil-Foundation-Structure System. Indo-Norwegian Training Programme on Seismic Design of Multi-storey Buildings: IS 1893 vs. Eurocode, New Delhi. 8 May 26-28. 2014

4. Jan Bunjak, Jaroslav Odrobinak, Josef Vican: Extradosed Bridge-Theoretical and Experimental Verification. Concrete and Concrete Structures 2013 Conference. Procedia Engineering 65 (2013) 327-334

5. José Benjumea, Gustavo Chio, Structural behavior and design criteria of Extradosed bridges. Vol. 25. No.3. Revista Ingeniería de Construcción. Dec.2010

6. A.Ogawa, and A.Kasuga: Extradosed bridges in Japan. FIP Notes. 1998

7. Drilon Rraci, Matic Ledinek, Iztok Videmšek: Extradosed Bridge-Scholar project design example. University of Maribor. Maribor. 2016 